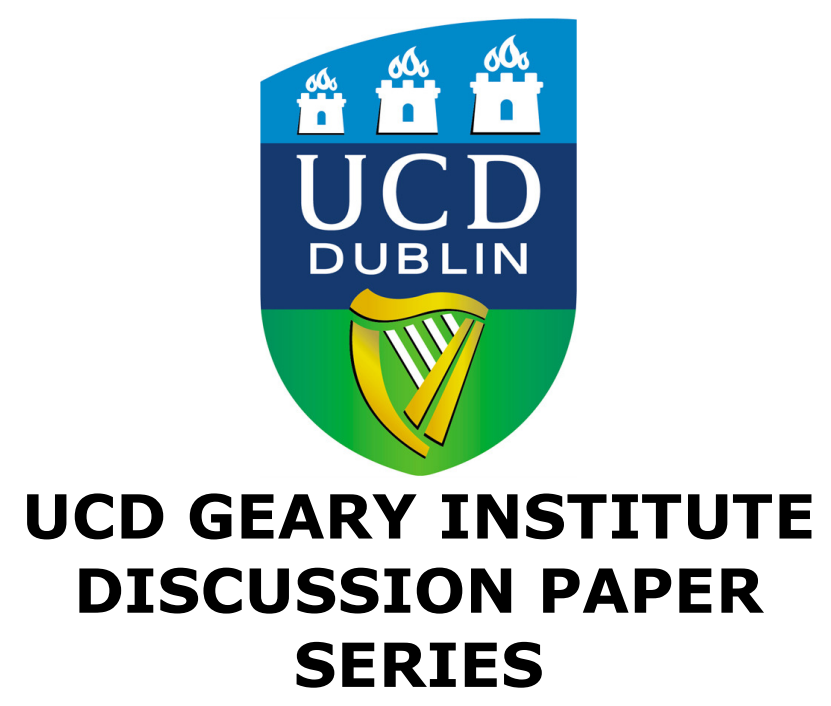

\title{
Psychological and Biological Foundations of Time Preference: Evidence from a Day Reconstruction Study with Biological Tracking
}

\author{
Michael Daly \\ School of Psychology, Trinity College Dublin \\ Liam Delaney \\ UCD Geary Institute, UCD School of Economics, UCD School of Public Health and Population Science \\ Colm Harmon \\ UCD Geary Institute, UCD School of Economics, IZA Bonn
}

\section{August 2008}


Preliminary Draft: August $10^{\text {th }} 2008$.

Comments Welcome

\begin{abstract}
This paper considers the relationship between the economic concept of time preference and relevant concepts from psychology and biology. Using novel data from a time diary study conducted in Ireland that combined detailed psychometric testing with medical testing and realtime bio-tracking, we examine the distribution of a number of psychometric measures linked to the economic concept of time preferences and test the extent to which these measures form coherent clusters and the degree to which these clusters are related to underlying biological substrates. The paper finds that financial discounting is related to a range of psychological variables including consideration of future consequences, self-control, conscientiousness, extraversion, and experiential avoidance as well as being predicted by heart rate variability and blood pressure.
\end{abstract}

*Corresponding Author: Liam Delaney, Room B102 UCD Geary Institute, UCD, Belfield, Dublin 4, Ireland. Email: Liam.Delaney@ucd.ie. We would like to acknowledge the contribution of Dr. Peter Doran and the clinical research nursing team at the Mater Misericordiae University Hospital: Jacqueline Breiden, Ann Marie Mulligan, Marcella Nunan, Marie Burke, and Eileen O'Connor. We are also grateful to Dr. David Murray, Brendan Igoe, and the laboratory analysis team at the UCD Clinical Research Centre. Thanks to James Heckman, Johan Mackenbach and seminar attendees at UCD, Oxford, ZEW Mannheim, and the MESS annual conference for comments. 


\section{Introduction}

The concept of time preference is central to economic theories of human behaviour. For example, models in health economics such as the Grossman model (Grossman, 1972) and the Theory of Rational Addiction (Becker and Murphy, 1988) rely heavily on concepts of time preferences and a growing body of research has been conducted to examine the realism of the assumptions of these models (Reynolds, 2006). Particularly, recent papers have examined the biological and psychological foundations of time preferences in humans (Borghans et al., 2008; Frederick et al, 2002; Heckman, 2008).

In order to map the theoretical work to an empirical specification it is important to have valid and reliable measures of time preferences that can be administered in the context of widescale surveys. To date, several economists have used behavioural proxies for time preferences but these have been criticised as being "error-laden" and associated with inconsistency across domains of behaviour (Heckman, 2007). Better measures and conceptualisation of time preferences would contribute to literatures in health economics, behavioural finance and several other areas of economics.

However, the extent to which economic measures of time preferences are related to psychological concepts is poorly understood. In particular, little is known to date about the relationship between time preferences and several plausibly related psychometric constructs such as future orientation, self-control, executive functioning, self-awareness, conscientiousness, and emotion regulation. Furthermore, while a body of work has emerged on the potential neural systems underlying time preferences (McClure et al, 2004; McClure et al, 2007), these papers have generally focused the interpretation of specific brain 'pathways' obtained via neural imaging techniques. Very little work has examined other biological mechanisms relating, for example, to sympathetic nervous system activation (e.g. 'flight or fight' responses) and endocrine (e.g. stress hormones) functioning which, a priori, seem also likely to be implicated in decision making over different time horizons.

In this paper we address these deficits directly using an innovative primary data source which incorporates standard socio-demographics measures, discounting questions, psychometric and biological measures. Specifically, we estimate time discounting as a function of this broader set of psychometric and biological measures to examine the relative plausibility of different determinants of discounting choices. The paper is structured as follows. Section 2 examines a number of plausible psychological and biological mechanisms that relate to human discounting. Section 3 describes the data and study procedures. Section 4 examines the results of a number of different tests of association between economic measures of time preferences and biological/psychological measures. Section 5 concludes. 


\section{Literature}

The most common paradigm in the economic analysis of time preferences is the hypothetical elicitation of preferences for monetary trade-offs, where individuals are asked to make hypothetical trade-offs between rewards delivered at different time intervals. Results from such studies reveal a number of cognitive effects including framing and salience effects (Frederick et al, 2002). Research on individual differences in discounting has focused on cognitive factors such as IQ and numeracy, executive functions such as working memory, and non-cognitive traits such as impulsivity and sensitivity to reward (Shamosh et al., In press; Reynolds et al., 2006).

Recent contributions have started to examine a broader range of potential non-cognitive psychological analogues to time preferences. Borghans et al (2008) argue that time preferences are linked to the psychological concepts of conscientiousness, impulsivity and the ability to imagine future states. Conscientiousness is one component of the so-called 'Big Five' personality taxonomy (the others being agreeableness, neuroticism, extraversion and openness to experience). While other components of the 'Big Five' could potentially be involved in future orientation (e.g. openness to experience may condition the set of alternatives conceived as future options), conscientiousness is particularly implicated in the ability to make sacrifices now for rewards later.

A trait which is closely related to the conscientiousness subcomponent of self-discipline is self-control. Self-control is an expansive concept that involves monitoring of self and regulation of behaviour in line with goals and self-imposed standards. In much of the recent literature, self-control has been conceived of as drawing from a limited resource (a willpower reserve) that can be attenuated by tasks requiring effortful control of attention (Vohs et al., 2008). The ability to utilise regulatory resources to actively regulate emotion and behaviour continuously through time in order to forego potential immediate rewards is likely to be strongly related to time preferences.

Resisting short-term reward in favour of longer term alternatives also requires a capacity to envision the distant outcomes of current choices. Future orientation is one of the psychometric constructs which is conceptually most closely related to time preferences. The main measure of future orientation examines the extent to which individuals tend to make sacrifices for later reward or act out of convenience as opposed to in line with long-term goals (Strathman et al, 1994). A related construct in decision making research is the capacity to generate and evaluate future counterfactuals which has been shown to relate to a tendency to consider future consequences (Yordanova et al., 2008).

Alongside the ability to think about future outcomes, when confronted with decisions involving potential rewards over different time horizons, effectively altering the trajectory of the emotional response to temporally more immediate 'hot' emotional stimuli is an essential part of time discounting. The role of emotion regulation in economic decisions has been discussed in a number of papers (Loewenstein and O'Donoghue, 2007). For example, it has been shown that emotion regulation influences the pattern of trading among financial investors and has even been shown to markedly diminish loss aversion in an experimental setting (Seo and Barrett, 2007; Camerer, 2008). Purposeful regulation of emotion early in the emotion-generation process involves reformulating the meaning of immediate affective stimuli and is associated with positive outcomes in terms of mood and life-satisfaction. Conversely, under-engagement with emotion is associated with more delayed processes which occur post emotion-generation such as a tendency to inhibit emotion expressive behaviours and emotion related thoughts and to avoid engagement with current experience (John and Gross, 2004). The later maladaptive emotion regulation strategies have been implicated in erratic and impulsive behaviour and may be involved in time discounting. 
Mood states may also have an independent influence on decision-making. In particular, experimentally induced negative emotional states have been shown to induce more impulsive responding. For instance, in a simulated fishing economy where participants could earn real money for harvesting a reasonable number of fish continuously over the course of the experiment, induced aversive emotional states caused initial overfishing and lower overall earnings (Knapp and Clark, 1991). Positive affect has been shown to reinforce self-control and may support future directed behaviour.

Health bio-markers have also been discussed in relation to discounting. For example, it has been shown that overweight and obese people tend to discount the future more than those of normal weight (Zhang and Rashad, 2007; Borghans and Golsteyn, 2006). Also, several economic models argue that individuals with higher discount rates will be more likely to invest poorly in health and thus have worse health than those with low discount rates.

In terms of more fully understanding the biological processes involved in time discounting, several recent studies have examined the neural substrates involved in decision making through time. McClure et al (2004) demonstrate differential limbic system activation in the presence of immediate monetary rewards. They replicate these results in the presence of primary rewards (McClure et al, 2007) and argue that discounting can be thought of in terms of dual interacting systems, with the emotion focused subcortical limbic system recruited for decisions involving immediate tradeoffs and the more cognitively orientated frontal-parietal system involved in discounting across all tradeoffs. However, less research has been conducted examining other biological research paradigms and the potential light that such paradigms might shed on economic discounting.

Glucose has been widely discussed in the psychological literature as an essential biological 'fuel' for self-control and decision making through time, involved particularly in the regulation of impulsive decisions and goal-directed behaviour (Gailliot et al., 2007). There is strong reason to believe that variation in glucose levels may provide information on the biological substrates implicated in economic discounting.

The extent to which autonomic sub-systems influence economic discounting has received little attention in the economics literature. While the relationship between self-control and heart rate variability has been examined in a number of papers (Segerstrom and Solberg, 2007), no paper to date has examined the potential role of heart rate variability in economic discounting. Given that many of the brain regions responsible for autonomic regulation have also been implicated in time discounting, this provides strong reason to believe that blood pressure, heart rate and heart rate variability may be important markers for similar processes to economic discounting. Indeed, several papers have suggested that heart rate variability provides an important marker of an adaptive response in decisions involving delayed reward. High and invariable heart rates have also been demonstrated to correlate with impulsivity (Krueger et al., 2005). Thus, integrating autonomic measures offers the potential to open up a new measurement paradigm in discounting studies, and one that is substantially more flexible and less invasive than the fMRI paradigms. 


\section{Study and Measures Used}

The data used in this paper is drawn from an on-campus study of students from Trinity College Dublin (TCD). Across most degree programmes TCD students are drawn from the upper portion of the distribution in terms of scores such as entry grades based on the Irish secondary school graduation examination. Students were recruited on-campus based on the response to a college wide email request for participation the study. A combination of monetary and course-credit incentives were offered in return for participation. In total 435 students responded to this email, and following initial communications about the nature and depth of the proposed work, a sample of 204 agreed to full participation. Sixty four percent of the sample were female and the mean age of the participants was 24.5 years $(\mathrm{SD}=6.5)$.

Each participant was given an initial medical test involving blood pressure, body fat impedance analysis, blood glucose, weight and height. This was completed on behalf of the study by the research nurse team at the Clinical Research Centre at the Mater Misericordiae Hospital in Dublin, a teaching hospital of University College Dublin. Respondents were then given instructions on the use of the portable heart monitoring devices. They wore these from waking on the following day until bedtime. Respondents were asked to provide four saliva samples over the course of this day at pre-determined intervals from waking - these intervals were common across all respondents. Finally, respondents on the third day completed a web-based questionnaire including the day reconstruction method (Kahneman et al., 2004a) and a large battery of psychometric and demographic tests. Table 1 outlines the measures and data instruments utilised throughout the programme of work.

In a follow-up study, respondents were asked to participate in an economic discounting study and 150 of the original 204 agreed. In this paper we estimate a simple specification of the form $D_{i}=f\left(X_{i}, P_{i}, B_{i}\right)$ where, for $i$ individuals, $D$ represents a measure of discounting behaviour, $X$ represents a set of socio-demographic variable, $P$ represents a set of psychometric measures and $B$ is a set of biological measures.

The measures of discounting behaviour used in the paper is a monetary task model following Kirby (1999), where respondents were offered a a fixed set of 27 binary choices between smaller, immediate rewards that the person can have today and larger, delayed rewards that the person can have at some date in the future. The participants were instructed to take the choices seriously, that choices may be for real money and that the money will be delivered to them at the appropriate time if they were to win. Each participant's choices were converted into a discount-rate parameter which is calculated as the geometric mean $\mathrm{k}$ value derived from indifference points approximations for small, medium and large rewards offered to respondents for each choice. Larger assigned discounted values indicate a greater tendency to discount the value of future rewards with the relationship between immediate and delayed rewards identified by the estimated $\mathrm{k}$ value as follows: $\mathrm{k}=\mathrm{A}-\mathrm{V} / \mathrm{V} * \mathrm{D}$, where $\mathrm{A}=$ the delayed value, $\mathrm{V}=$ the immediate value, and $D=$ the magnitude of the delay (see Kirby et al. (1999), for the table of payoffs used, and details regarding the computation of individual discount rates). A second binary measure assessed choice consistency defined as selecting a delayed option associated with a lower $\mathrm{k}$ value than another choice where the participant selected an immediate option.

Table 1 outlines the measures and data instruments utilised (the $P$ and $B$ variables) throughout the estimations, with a set of prior assumptions about the manner of effect of these variables based on the appropriate literatures. 
Table 1: Measures Used in the Study

\begin{tabular}{|c|c|c|}
\hline & Explanation & Prior Assumptions on Impact \\
\hline Monetary Choice Task & $\begin{array}{l}\text { Respondents are offered a series of } 27 \text { choices } \\
\text { involving monetary rewards at different time } \\
\text { intervals. Measures the extent to which individuals } \\
\text { discount the value of future financial outcomes. }\end{array}$ & Dependent Variable \\
\hline $\begin{array}{l}\text { Ten Item Personality } \\
\text { Inventory: }\end{array}$ & $\begin{array}{l}\text { Short-form Big Five Inventory assessing the broad } \\
\text { dimensions of personality: Extraversion, } \\
\text { Agreeableness, Conscientiousness, Neuroticism, } \\
\text { and Openness (Gosling et al., 2003) }\end{array}$ & $\begin{array}{l}\text { Extraversion, low Conscientiousness } \\
\text { and Neuroticism associated with a } \\
\text { higher discount rate. }\end{array}$ \\
\hline Self-Control Scale: & $\begin{array}{l}\text { A 13-item measure which captures individual } \\
\text { differences in the ability to exercise self-control in } \\
\text { controlling impulses, emotions, thoughts, and } \\
\text { performance (Tangney et al., 2004). }\end{array}$ & $\begin{array}{l}\text { Higher Self-Control associated with } \\
\text { lower discounting }\end{array}$ \\
\hline $\begin{array}{l}\text { Consideration of Future } \\
\text { Consequences Scale: }\end{array}$ & $\begin{array}{l}\text { The CFC is a 12-item subjective elicitation measure } \\
\text { focused on future orientations. The CFC is a } \\
\text { measure of the extent to which people consider and } \\
\text { are influenced by the distant outcomes of their } \\
\text { current behaviour (Strathman et al 1994). }\end{array}$ & $\begin{array}{l}\text { Higher consideration of the future } \\
\text { associated with lower discounting }\end{array}$ \\
\hline $\begin{array}{l}\text { Elaboration of Potential } \\
\text { Outcomes: }\end{array}$ & $\begin{array}{l}\text { Measures the extent to which individuals generate } \\
\text { positive and negative consequences of their } \\
\text { behaviours and captures the degree to which they } \\
\text { evaluate the likelihood and importance of such } \\
\text { consequences (Yordanova et al., 2006). }\end{array}$ & $\begin{array}{l}\text { High Elaboration associated with lower } \\
\text { discount. }\end{array}$ \\
\hline $\begin{array}{l}\text { Emotional Regulation } \\
\text { Questionnaire: }\end{array}$ & $\begin{array}{l}\text { Captures two common emotional regulation } \\
\text { strategies: (1) cognitive reappraisal or changing } \\
\text { how one thinks about an emotion-eliciting event, } \\
\text { (2) expressive suppression or reducing the } \\
\text { behavioural expression of emotion when one is in } \\
\text { an emotional state (John \& Gross, 2004). }\end{array}$ & $\begin{array}{l}\text { Suppression of emotional expression } \\
\text { associated with a higher discount rate } \\
\text { and reappraisal of emotion associated } \\
\text { with a lower rate of discounting. }\end{array}$ \\
\hline $\begin{array}{l}\text { Cognitive and Affective } \\
\text { Mindfulness } \\
\text { Questionnaire-Revised }\end{array}$ & $\begin{array}{l}\text { A 12-item scale assessing the attention, awareness, } \\
\text { present-focus, and acceptance/nonjudgement facets } \\
\text { of the mindfulness construct (Feldman at al., 2007). }\end{array}$ & $\begin{array}{l}\text { Higher Mindfulness associated with } \\
\text { lower discounting }\end{array}$ \\
\hline $\begin{array}{l}\text { White Bear Suppression } \\
\text { Inventory: }\end{array}$ & $\begin{array}{l}\text { Self-report measure assessing the general tendency } \\
\text { to suppress unwanted thoughts which is associated } \\
\text { with obsessive thinking and emotional reactivity } \\
\text { (Wegner and Zanakos, 1994). }\end{array}$ & $\begin{array}{l}\text { Higher levels of Thought Suppression } \\
\text { associated with higher discount. }\end{array}$ \\
\hline $\begin{array}{l}\text { Acceptance and Action } \\
\text { Questionnaire: }\end{array}$ & $\begin{array}{l}\text { Measures experiential avoidance: the tendency to } \\
\text { negatively evaluate and avoid contact with } \\
\text { particular private experiences (e.g. emotions, } \\
\text { sensations, memories) (Hayes et al., 2004). }\end{array}$ & $\begin{array}{l}\text { Greater Experiential Avoidance } \\
\text { associated with higher discounting. }\end{array}$ \\
\hline $\begin{array}{l}\text { Day Reconstruction } \\
\text { Method: }\end{array}$ & $\begin{array}{l}\text { The DRM is a measure of evaluated time-use } \\
\text { which assesses the experience of daily affect } \\
\text { through eliciting ratings of episodes experienced by } \\
\text { respondents (Kahneman et al., 2004b). }\end{array}$ & $\begin{array}{l}\text { Positive affect associated with lower } \\
\text { discounting. Negative affect associated } \\
\text { with higher discounting. }\end{array}$ \\
\hline Health Bio-markers & $\begin{array}{l}\text { Body fat (estimated percentage of total mass) and } \\
\text { Body Mass Index (BMI) were assessed. }\end{array}$ & $\begin{array}{l}\text { Higher BMI and body fat associated } \\
\text { with higher discounting. }\end{array}$ \\
\hline $\begin{array}{l}\text { Autonomic nervous } \\
\text { system monitoring: }\end{array}$ & $\begin{array}{l}\text { Heart rate was continuously tracked from waking to } \\
\text { sleeping. Resting blood pressure was also assessed. }\end{array}$ & $\begin{array}{l}\text { Higher heart rate variability, lower } \\
\text { heart rate and lower blood pressure } \\
\text { associated with lower discounting. }\end{array}$ \\
\hline Glucose Monitoring: & $\begin{array}{l}\text { Blood Glucose was measured using a pin-prick test } \\
\text { at the beginning of the study. }\end{array}$ & $\begin{array}{l}\text { Low Glucose associated with higher } \\
\text { discounting. }\end{array}$ \\
\hline
\end{tabular}




\section{Results}

\subsection{Descriptive Statistics}

Table 2 displays descriptive statistics on key variables used in the study. It also displays the raw correlation of each variable with the discount scores calculated based on responses in the financial discounting task. The correlations reveal that lower discounting in the financial discounting task is associated with high scores on conscientiousness, self-control, consideration of future consequences, cognitive/affective mindfulness, and low scores on experiential avoidance and extraversion.

Table 2: Descriptive Statistics on Psychometric Variables and Raw Correlation with

\section{Discount Parameter}

\begin{tabular}{|l|c|c|c|c|c|c|}
\hline Variable & Obs & Mean & Std. Dev. & Min & Max & k value \\
\hline Conscientiousness & 149 & 9.46 & 2.79 & 2 & 14 & $-0.15^{*}$ \\
\hline Extraversion & 149 & 9.43 & 2.79 & 3 & 14 & $0.16^{* *}$ \\
\hline Nervousness & 149 & 7.07 & 3.02 & 2 & 14 & 0.11 \\
\hline Openness & 149 & 10.95 & 2.23 & 5 & 14 & 0.01 \\
\hline Agreeableness & 149 & 9.76 & 2.15 & 2 & 14 & -0.11 \\
\hline Self-Control Scale & 149 & 39.49 & 8.32 & 18 & 59 & $-0.14^{* *}$ \\
\hline Consideration of Future Consequences & 149 & 43.30 & 7.15 & 24 & 57 & $-0.18^{* *}$ \\
\hline Elaboration & 149 & 29.01 & 6.30 & 12 & 42 & -0.11 \\
\hline Positive Elaboration & 149 & 13.99 & 4.06 & 3 & 21 & -0.02 \\
\hline Negative Elaboration & 149 & 15.54 & 6.02 & 4 & 28 & 0.07 \\
\hline Cognitive Reappraisal & 149 & 26.73 & 6.14 & 12 & 41 & 0.10 \\
\hline Expressive Suppression & 149 & 12.58 & 4.93 & 4 & 26 & -0.03 \\
\hline Cognitive Affective Mindfulness Scale & 149 & 31.06 & 5.28 & 20 & 44 & $-0.13^{*}$ \\
\hline Thought Suppression & 149 & 40.97 & 12.90 & 15 & 70 & 0.07 \\
\hline Experiential Avoidance & 149 & 34.24 & 6.41 & 18 & 51 & $0.26^{* * *}$ \\
\hline Positive Affect & 147 & 21.17 & 4.57 & 1.07 & 33.29 & -0.07 \\
\hline Negative Affect & 147 & 5.44 & 3.09 & 0.08 & 15.50 & 0.02 \\
\hline
\end{tabular}

Significance levels $* * * \mathrm{p}<0.01, * * \mathrm{p}<0.05, * \mathrm{p}<0.1$

Table 3 displays descriptive statistics on a number of biological markers: mean heart rate; standard deviation of heart rate; systolic and diasystolic blood pressure; as well as the correlation of these variables with the discount rate displayed in the financial task. As can be seen, discount rates correlate negatively with heart rate variability and positively with blood pressure.

Table 3: Descriptive Statistics on Biological Variables and Correlation with Discount Parameter

\begin{tabular}{|l|c|c|c|c|c|c|}
\hline Variable (units) & Obs & Mean & Std. Dev. & Min & Max & k value \\
\hline Body Fat $(\%)$ & 149 & 28.66 & 8.37 & 10.90 & 47.30 & -0.12 \\
\hline BMI (kg/m²) & 149 & 23.18 & 3.88 & 13.50 & 45.23 & 0.12 \\
\hline R-R (interbeat interval) & 139 & 723.94 & 108.77 & 505.21 & 1137.15 & -0.06 \\
\hline HRV (SD of R-R) & 139 & 141.65 & 45.86 & 66.65 & 343.73 & $-0.15^{*}$ \\
\hline Sys BP (mmHg) & 149 & 123.43 & 12.94 & 85.00 & 159.00 & $0.29^{* * *}$ \\
\hline Dia BP (mmHg) & 149 & 69.48 & 9.72 & 52.00 & 103.00 & 0.13 \\
\hline Glucose (mmol/L) & 148 & 5.22 & 0.69 & 3.30 & 8.30 & -0.11 \\
\hline
\end{tabular}

Significance levels $* * * \mathrm{p}<0.01, * * \mathrm{p}<0.05, * \mathrm{p}<0.14 .2$ Factor analysis of measures 
The extent to which this large array of proxies for time preferences can be reduced to a smaller number of underlying dimensions can be examined through factor analysis. The rotated factor matrix from a factor analysis is displayed in Table 4 below. Four factors with eigen values greater than one emerged from the analysis. The first factor is associated in particular with high values on positive affect and positive elaboration and low values on neuroticism, negative elaboration, and experiential avoidance. It is reasonable to think of this factor as representing a dispositional trait toward higher well-being. The second factor is associated, in particular, with self-control, consideration of future consequences, elaboration of consequences, cognitive/affective mindfulness and conscientiousness. It thus loads well on several well-known constructs conceptually related to economic discounting. The third factor is clearly heart rate level and variability and the fourth factor is blood pressure.

Table 4: Rotated Factor Matrix

\begin{tabular}{|l|c|c|c|c|}
\hline Variable & Factor1 & Factor2 & Factor3 & Factor4 \\
\hline Conscientiousness & -0.13 & 0.73 & -0.13 & 0.03 \\
\hline Extraversion & -0.40 & -0.23 & 0.15 & -0.18 \\
\hline Nervousness & 0.70 & -0.08 & 0.21 & 0.12 \\
\hline Openness & -0.03 & -0.23 & 0.23 & 0.02 \\
\hline Agreeableness & -0.20 & 0.21 & 0.18 & 0.08 \\
\hline Self-Control Scale & -0.18 & 0.78 & -0.15 & -0.01 \\
\hline Consideration of Future Consequences & 0.06 & 0.58 & 0.07 & -0.03 \\
\hline Elaboration & 0.07 & 0.60 & 0.19 & -0.08 \\
\hline Positive Elaboration & -0.69 & -0.03 & 0.15 & -0.07 \\
\hline Negative Elaboration & 0.72 & -0.02 & 0.09 & -0.08 \\
\hline Cognitive Reappraisal & -0.22 & 0.21 & 0.28 & -0.16 \\
\hline Expressive Suppression & 0.29 & 0.03 & -0.20 & 0.00 \\
\hline Cognitive Affective Mindfulness Scale & -0.57 & 0.51 & -0.01 & 0.09 \\
\hline Thought Suppression & 0.57 & -0.23 & 0.00 & -0.13 \\
\hline Experiential Avoidance & 0.68 & -0.34 & -0.03 & -0.06 \\
\hline Positive Affect & -0.43 & 0.00 & 0.24 & -0.25 \\
\hline Negative Affect & 0.56 & 0.10 & 0.11 & 0.17 \\
\hline Body Fat & 0.00 & 0.11 & 0.32 & 0.12 \\
\hline BMI & -0.08 & -0.09 & -0.01 & 0.52 \\
\hline Heart Rate & -0.03 & 0.09 & -0.76 & 0.04 \\
\hline Heart Rate Variability & -0.12 & 0.14 & -0.62 & -0.08 \\
\hline Systolic blood pressure & 0.02 & -0.05 & -0.08 & 0.76 \\
\hline Diasystolic blood pressure & 0.06 & 0.16 & 0.28 & 0.58 \\
\hline Blood glucose & 0.01 & -0.03 & -0.04 & 0.30 \\
\hline
\end{tabular}




\subsection{Determinants of Financial Discounting}

We use the four constructed variables, along with age and gender as covariates in models of patience in the discounting task. The results are displayed in Table 5. As can be seen, neither age nor gender exerts a significant influence on the patterns involved. However, age is associated with a significantly lower probability of choice inconsistency. Factor 2 is significantly associated with greater patience in the financial discounting task and this is robust to several different methods of scoring the discounting task and of specifying the error distributions. Factor 1 is significant and positive in some models though this depends on the handling of outliers and the error specifications. Similarly, Factor 4 (representing blood pressure) predicts discounting in the expected direction and is significant in several models.

Table 5: Determinants of Financial Discounting

\begin{tabular}{|l|l|l|l|l|l|l|l|l|}
\hline & & Age & Gender & F1 & F2 & F3 & F4 & Constant \\
\hline \multirow{3}{*}{ Discount Rate } & Coefficient & 0.000 & -0.002 & -0.001 & $\begin{array}{l}-0.003 \\
* * *\end{array}$ & -0.001 & $0.002 *$ & $0.011^{* *}$ \\
\cline { 2 - 9 } & Std Error & $(0.000)$ & $(0.002)$ & $(0.001)$ & $(0.001)$ & $(0.001)$ & $(0.001)$ & $(0.005)$ \\
\hline \multirow{2}{*}{ Inconsistency } & Coefficient & $-0.047 *$ & -0.036 & 0.029 & -0.001 & -0.020 & $0.308^{*}$ & 0.468 \\
\cline { 2 - 9 } & Std Error & $(0.026)$ & $(0.308)$ & $(0.137)$ & $(0.138)$ & $(0.155)$ & $(0.166)$ & $(0.747)$ \\
\hline
\end{tabular}

Significance levels $* * * \mathrm{p}<0.01, * * \mathrm{p}<0.05,{ }^{*} \mathrm{p}<0.1$ 


\section{Discussion}

In this paper we examined the relationship between economic discounting and a range of psychological and biological variables. Our results suggest that financial discounting is associated with a number of variables measuring future orientation. The results of a factor analysis incorporating measures of self-control, cognitive appraisal, emotional regulation, personality, heart rate functioning, blood pressure, and blood glucose yielded four main factors: affect; selfcontrol; heart rate; and blood pressure. In particular, there is strong evidence that self-control has a strong independent effect on measures of patience in financial discounting tasks. Furthermore, there is some evidence to support the claim that affect has a role in discounting and that heart rate variability and blood pressure are associated with discounting. This is the first time that such an analysis has been conducted in the context of economic discounting and it lends substantial evidence to a number of theoretical accounts of decision making that examine the linkages between psychological, biological and economic models of discounting.

This work is clearly not without limitations. As stressed by Borghans et al (2008) and in the dynamic models of human capital formation of Heckman (2006), the potential interplay between measures (so that an intervention that changes the expression of some biological characteristic could lead to an alternative path for cognitive or non-cognitive outcomes) is missing from this analysis. The linear nature of the models presented in this paper clearly represents only a first start in what will be a lengthy literature. However, this paper brings together in one exploratory dataset the key components to address the emerging literature on the interplay between biological, psychological and social determinants of economic behaviour. The extent to which concepts such as self-control, future orientation, conscientiousness and others can be arranged into hierarchical systems is a key task for future research.

The future of this research will utilise larger samples to overcome power limitations and will also incorporate panel data in order to examine dynamic changes in the variables and their effect on discounting over time. In terms of expanding the current scope of variables assessed, conceptually related constructs such as sensation seeking, numeracy, and sustained attention will be incorporated in subsequent rounds of the study and discounting will be examined across a wider set of domains and time horizons. Where feasible, the examination of the effect of within person manipulation of psychological and biological variables on delay discounting will be evaluated through experiments. This will allow more robust inferences to be made regarding the causal role of these variables in determining time preferences. 


\section{References}

Appelhans, B. \& Luecken, L., 2006. Heart rate variability as an index of regulated emotional responding. Review of general Psychology 10, 229-240.

Becker, G.S. \& Mulligan, C.B., 1997. The endogenous determination of time preference. The Quarterly Journal of Economics 112(3), 729-758.

Becker, G.S., \& Murphy, K.M., 1988. A Theory of Rational Addiction. Journal of Political Economy 964, 675-700.

Borghans, L. \& Golsteyn, B., 2006. Time Discounting and the Body Mass Index, Economics and Human Biology 4(1), 39-6.

Borghans, L., Duckworth, A.L., Heckman, J.J., \& ter Weel, B., 2008 (forthcoming). The Economics and Psychology of Personality traits. Journal of Human Resources 43(4).

Camerer C.F., Loewenstein G, Prelec D, 2004. Neuroeconomics: Why economics needs brains. Scandinavian Journal of Economics 106, 555-579.

Camerer, C.F., 2008. The Case for Mindful Economics, in Caplin, A., and Schotter, A. (ed.), Foundations of Positive and Normative Economics. New York: Oxford University Press.

Feldman, G. C., Hayes, A. M., Kumar, S. M., Greeson, J. M., \& Laurenceau, J. P., 2007. Mindfulness and emotion regulation: The development and initial validation of the cognitive and affective mindfulness scale-revised (CAMS-R). Journal of Psychopathology and Behavioral Assessment 29, 177-190.

Frederick, S., Loewenstein, G., \& O' Donoghue, T., 2002. Time discounting and time preference: a critical review. Journal of Economic Literature 40, 350-401.

Gailliot, M.T., Baumeister, R.F., DeWall, C.N., Maner, J.K., Plant, E.A., Tice, D.M., et al., 2007. Selfcontrol relies on glucose as a limited energy source: Willpower is more than a metaphor. Journal of Personality and Social Psychology 92, 325-336.

Gosling, S.D., Rentfrow, P.J. \& Swann, W.B., 2003. A very brief measure of the Big Five personality domains. Journal of Research in Personality, 37, 504-528.

Grossman, M., 1972. On the concept of health capital and the demand for health. Journal of Political Economy 80, 223-255

Heckman, J, J., (June, 2008). Schools, Skills, and Synapses. NBER Working Paper No. W14064 Available at SSRN: $\underline{\text { http://ssrn.com/abstract }=1142236}$

Hayes, S. C. et al., 2004. Measuring experiential avoidance: A preliminary test of a working model. The Psychological Record 54, 553-578.

Heckman, J. J., 2007. The Economics, Technology and Neuroscience of Human Capability Formation. Proceedings of the National Academy of Sciences 104(3), 13250-13255.

John, O.P., \& Gross, J.J., 2004. Healthy and unhealthy emotion regulation: Personality processes, individual differences, and lifespan development. Journal of Personality 72, 13011334.

Kahneman, D., Krueger, A.B., Schkade, D., Schwarz, N., \& Stone, A.A., 2004a. Toward national wellbeing accounts. AEA Papers and Proceedings 94, 429-34. 
Kahneman, D., Krueger, A.B., Schkade,D.A., Schwarz, N. and Stone, A.A., 2004b, A Survey Method for Characterizing Daily Life Experience: The Day Reconstruction Method. Science 306(5702), 1776-80.

Kirby, K. N., Petry, N. M., \& Bickel, W. K., 1999. Heroin addicts have higher discount rates for delayed rewards than non-drug-using controls. Journal of Experimental Psychology: General 128(1), 78-87.

Knapp, A., \& Clark, M. S., 1991. Some detrimental effects of negative mood on individuals' ability to solve resource dilemmas. Personality and Social Psychology Bulletin 17, 678-688.

Krueger, T.H., Schedlowski, M., \& Meyer, G., 2005. Cortisol and heart rate measures during casino gambling in relation to impulsivity. Neuropsychobiology 52(4), 206-11.

Frederick, S., Loewenstein, G., O’Donoghue, T., 2002. Time discounting and time preference: A critical review. Journal of Economic Literature 40, 351-401

Loewenstein, G. and O'Donoghue, T., 2007. The heat of the moment: Modeling interactions between affect and deliberation. Working Paper. Carnegie Mellon University.

McClure, S.M., Laibson, D.I., Loewenstein, G., \& Cohen, J.D., 2004. Separate neural systems value immediate and delayed monetary rewards. Science 306, 503-507.

McClure, S.M., Ericson, K.M., Laibson, D.I., Loewenstein, G., \& Cohen, J.D., 2007. Time discounting for primary rewards. Journal of Neuroscience 27, 5796-5804.

Nenkov, G., Inman, J.J., \& Hulland, J., 2008. Considering the Future: The conceptualization and measurement of elaboration on potential outcomes. Journal of Consumer Psychology 35, 126-141.

Reynolds, B., 2006. A review of delay-discounting research with humans: Relations to drug use and gambling. Behavioural Pharmacology 17, 651-667.

Reynolds, B., Ortengren, A., Richards, J.B., et al, 2006. Dimensions of impulsive behavior: Personality and behavioral measures. Personality and Individual Differences 40 (2), 305-315.

Segerstrom, S.C. \& Solberg Nes, L., 2007. Heart Rate Variability Reflects Self-Regulatory Strength, Effort, and Fatigue. Psychological Science 18(3), 275-281.

Seo, M., \& Barrett, L.F., 2007. Being emotional during decision making- good or bad? The Academy of Management Journal 50(4), 923-940.

Shamosh, N. A., \& Gray, J. R., In press. Delay discounting and intelligence: A meta-analysis.

Intelligence.

Strathman, A. et al., 1994. The consideration of future consequences: weighing immediate and distant outcomes of behavior. Journal of Personality and Social Psychology 66, 742-752.

Tangney, J. P., Baumeister, R. F., \& Boone, A. L., 2004. High self-control predicts good adjustment, less pathology, better grades, and interpersonal success. Journal of Personality 72, 271-322.

Vohs, K. D., et al., 2008. Making Choices Impairs Subsequent Self-Control: A Limited-Resource Account of Decision Making, Self-Regulation, and Active Initiative. Personality Processes and Individual Differences 94(5), 883-898.

Wegner, D. M., \& Zanakos, S., 1994. Chronic thought suppression. Journal of Personality 62(4), 615-640. 
Zhang, L., \& Rashad, I., 2007. Obesity and time preference: The health consequences of discounting the future. Journal of Biosocial Science 40, 97-113. 